\title{
Diabetic Neuropathy: Models, Mechanisms and Mayhem
}

\author{
P.K. Thomas
}

\begin{abstract}
Rational treatment of diabetic polyneuropathy depends upon establishing its cause, which is at present unknown. A number of animal models of diabetes have been examined and although abnormalities are detectable in the peripheral nervous system they do not duplicate the degenerative neuropathy encountered in the human. The relevance of these abnormalities is therefore uncertain, although they may reflect the earlier changes in man. For human neuropathy, it is likely that vascular lesions or an abnormal susceptibility to mechanical injury are responsible for focal neuropathies. The evidence that ischaemia and hypoxia are responsible for the diffuse sensory neuropathy and autonomic polyneuropathy is still equivocal and it is often difficult to establish whether the vascular changes are primary or secondary. Metabolic explanations, such as sorbitol accumulation in nerve, have not so far been adequately validated by responses to treatment. The manifestations of diabetic neuropathy are complex and a single explanation should not be sought.
\end{abstract}

RÉSUMÉ: Neuropathie diabétique: modèles, mécanismes et ambiguités. Un traitement rationnel de la polyneuropathie diabétique dépendra de la découverte de sa cause, actuellement inconnue. Un certain nombre de modèles animaux du diabète ont été étudies et, même si des anomalies sont détectables au niveau du système nerveux périphérique, elles ne reproduisent pas la neuropathie dégénérative rencontrée chez l'humain. La pertinence de ces anomalies est donc incertaine, même si elles reflètent peut-être les changements précoces observés chez l'humain. Dans la neuropathie humaine, il est probable que les lésions vasculaires ou une susceptibilité anormale aux blessures mécaniques sont responsables des neuropathies focales. L'évidence que l'ischémie et l'hopoxie sont responsables de la neuropathie sensitive diffuse et de la polyneuropathie neurovégétative est encore incertaine et il est souvent difficile d'établir si les changements vasculaires sont primaires ou secondaires. Les explications métaboliques, telles que l'accumulation de sorbitol dans les nerfs, n'ont pas été adéquatement validées jusqu'ici par la reponse thérapeutique. Les manifestations de la neuropathie diabétique sont complexes et une explication unique ne sera pas suffisante pour les élucider.

Can. J. Neurol. Sci. 1992; 19:1-7

Satisfactory treatment for diabetic neuropathy is currently not available. It is known that strict glycemic control, either by continuous subcutaneous insulin infusion ${ }^{1}$ or pancreatic transplantation ${ }^{2}$ will stabilize the neuropathy, although little improvement has been detected over periods of up to 2 years. Neither of these forms of treatment is practical except in special circumstances or for research purposes. With conventional treatment it is difficult to obtain satisfactory glycemic control in a high proportion of patients, either because of poor compliance or because of 'brittle' diabetes. It is therefore imperative to establish the mechanism of diabetic neuropathy so that, if possible, its occurrence can be prevented even if adequate glycemic control cannot be obtained. This article will review current ideas as to the causation of peripheral neuropathy in patients with dia- betes mellitus, but first it is necessary to describe briefly what is being caused. It is clear that a wide variety of disturbances of peripheral nerve function may be encountered.

\section{Classification of Diabetic Neuropathy}

It is convenient to recognize two broad categories of peripheral nerve disturbance related to diabetes. These can be termed rapidly reversible phenomena and more persistent or "established neuropathy'.

Rapidly reversible phenomena include evanescent sensory symptoms such as pain and dysesthesia, experienced mainly in the lower limbs in poorly controlled patients, that rapidly resolve once glycemic control is established. The second is the

From the Royal Free Hospital School of Medicine and Institute of Neurology, London, UK

Received September 10, 1991. Accepted October 8, 1991

Based on the Richardson Lecture delivered at the 26th Meeting of the Canadian Congress of Neurological Sciences, Halifax, N.S., June 1991 Reprint requests to: P.K. Thomas, Department of Neurological Science, Royal Free Hospital School of Medicine, Rowland Hill Street, London, England NW3 2PF 
reduced nerve conduction velocity that is found in such patients and which improves with a time course that is too rapid for remyelination or regeneration to have been responsible. ${ }^{3,4}$ Finally, there is the phenomenon of abnormal resistance to ischemic conduction failure, ${ }^{5,6}$ shared by other groups of patients such as those with uremia, hepatic failure, chronic respiratory failure and motor neuron disease, and which is also seen with aging. At present there is no indication that these rapidly reversible phenomena are predictors for established diabetic neuropathy. They will therefore not be considered further.

More persistent or 'established' diabetic neuropathy is again subdivisible into two categories. The first consists of focal and multifocal neuropathies including isolated cranial nerve palsies, thoracoabdominal neuropathy, focal limb neuropathies and the proximal asymmetric lower limb motor neuropathy (diabetic amyotrophy). The second category includes approximately symmetric syndromes of which the most important examples are the sensory and autonomic polyneuropathies. These constitute the commonest types of diabetic neuropathy and once they have appeared are largely irreversible. They frequently coexist. The second category also includes the reversible syndrome of acute painful diabetic neuropathy ${ }^{7}$ and the chronic proximal symmetric lower limb motor neuropathy. ${ }^{8}$

\section{Animal Models of Diabetic Neuropathy}

A number of different models of diabetes have been used in attempts to provide an acceptable animal model for human diabetic neuropathy. Those most extensively investigated include the destruction of pancreatic beta cells by alloxan or streptozotocin, and spontaneous diabetes in the BB Wistar rat, both of which are models of type 1 insulin-dependent diabetes, and the recessively inherited diabetic $(\mathrm{C} 57 \mathrm{BL} / \mathrm{Ks}, \mathrm{db} / \mathrm{db})$ mouse, a model of type 2 non-insulin-dependent diabetes. All share impairment of the normal maturational increase in nerve conduction velocity and nerve fiber size. Loss of nerve fibers or demyelination that is any way comparable to that seen in human diabetic neuropathy does not occur, but this may be a question of the duration of the diabetes. Sima et al. ${ }^{9}$ have described paranodal swelling and 'axoglial dysjunction' in the BB rat, and also in the streptozotocin-diabetic rat, ${ }^{10}$ but these features have not been found either in the streptozotocin-diabetic rat or in the $\mathrm{db} / \mathrm{db}$ mouse in personal observations. How useful these animal models are for the interpretation of diabetic neuropathy is therefore problematic. It is hoped that they may provide clues to events occurring in the early stages of the human disease.

\section{The Causation of Diabetic Neuropathy}

Once the possible mechanisms for diabetic neuropathy are considered, the mayhem becomes evident. There has been a wealth of conflicting proposals. Currently the main contending views are those in which vascular disease is considered to underlie the totality of diabetic neuropathy and those in which a metabolic basis is favored, at least for the symmetric polyneuropathies.

\section{The Vascular Hypothesis}

\section{Large Vessel Disease}

Ischemia and hypoxia in the causation of diabetic neuropathy have had a chequered career. At the time the clinical features of diabetic neuropathy were being delineated a century ago, one of the earliest suggested causes was ischemia." This view was reiterated by Woltman and Wilder, ${ }^{12}$ who attributed the peripheral nerve damage to large vessel occlusive vascular disease. This study, although it had a major impact, suffered from the drawback that it was based partly on observations on nerve from amputated limbs and partly on autopsy material from patients who had had longstanding diabetes, in both of which the likelihood of coexistent atherosclerosis would have been high. Moreover, Renaut corpuscles, a normal feature of peripheral nerve, were misinterpreted as infarcts.

Peripheral nerve involvement in patients with occlusive vascular disease, although it occurs, tends not to be a major component of the clinical picture. ${ }^{13,14}$ The demand for oxygenation by peripheral nerve is presumably less than that by other tissues in the lower limbs. Chopra and Hurwitz ${ }^{15}$ compared the changes in nerve conduction in patients with lower limb ischemic vascular disease with those in patients with diabetic neuropathy and found distinct differences. The reduction in nerve conduction velocity was substantially greater in patients with diabetic neuropathy, this being correlated histologically with more pronounced demyelination in nerve biopsies. ${ }^{16}$ It has come to be accepted that large vessel occlusive disease does not play an important role in the production of peripheral nerve damage in diabetic neuropathy. Nevertheless, accompanying large vessel disease may influence the manifestations of diabetic neuropathy. The pattern of sensory loss differs in patients with diabetic polyneuropathy with and without evidence of accompanying peripheral vascular disease (P.J. Watkins, personal communication). Loss of vibration sense is more pronounced in the presence of vascular disease.

\section{Small Vessel Disease}

Interest in microvascular disease in diabetes began with the studies of Lundbaek which were applied to peripheral neuropathy by Fagerberg, ${ }^{17}$ who found evidence of abnormality affecting the small blood vessels in nerve biopsies from patients with diabetic neuropathy. This took the form of thickening of the walls of endoneurial vessels by PAS-positive material, later shown by electron microscopy to consist of reduplicated basal lamina. Microvascular disease was therefore proposed as the explanation for diabetic neuropathy. Other investigators, however, were unable to find a good correlation between neuropathy and small vessel disease, ${ }^{18-21}$ and possible metabolic explanations began to assume a dominant position. In recent years vascular disease has been revived as an explanation both for focal and generalized diabetic neuropathy. The evidence for and against this view will now be analysed. In doing so it is helpful to distinguish between focal and multifocal neuropathies, on the one hand, and the distal symmetric sensory/autonomic polyneuropathy on the other.

\section{Focal and Multifocal Neuropathy}

Although not substantiated by epidemiologic studies, it is generally accepted that focal neuropathies are more frequent in patients with diabetes mellitus than in the general population. These are often at the common sites of entrapment or external compression and appear to reflect an unexplained susceptibility of diabetic nerve to compression. Whether ischemia plays any part in this is not established. In entrapment neuropathy, the 
changes in nondiabetic subjects indicate that the major pathologic feature is displacement of myelin ${ }^{22}$ although the production of the acroparesthesiae in the carpal tunnel syndrome is likely to depend upon superimposed ischemia. ${ }^{23}$ Arguments that the carpal tunnel syndrome is ischemic in origin ${ }^{24}$ are not persuasive. It is not known whether the pathology for entrapment neuropathies in diabetic individuals differs from that in nondiabetic subjects.

The acute onset of focal neuropathies, such as an isolated third cranial nerve palsy, would be consistent with an ischemic basis, although the usually prompt recovery is not typical of ischemic peripheral nerve lesions. It is explained by the underlying pathology which is demyelinating, ${ }^{25}$ this again being atypical of vascular lesions in nerve. ${ }^{26}$ In an extensive serial section study on a patient who died 3 weeks after developing an acute third nerve lesion, Asbury, et al. ${ }^{25}$ found a focal area of centrifascicular demyelination with preservation of axonal continuity. Although not clearly related to vascular occlusion, it was considered to lie in a 'watershed' area and thus to be consistent with an ischemic process.

The report by Raff et al. ${ }^{27}$ on a patient with a proximal asymmetric lower limb motor neuropathy (diabetic amyotrophy) provides a less convincing demonstration. As in the study by Woltman and Wilder, ${ }^{2}$ Renaut corpuscles were misconstrued as infarcts. Apart from this, the evidence for ischemic damage depended upon the demonstration of areas of 'pallor' affecting small cross-bridging nerve bundles between larger fascicles. The interpretation of these areas, from the histologic appearances provided, is uncertain.

It has to be concluded, therefore, that although it is highly likely that many focal nerve lesions in patients with diabetes are ischemic in origin, further documentation is required to substantiate this.

\section{Generalized Polyneuropathies}

\section{Clinical Features}

The most common type of neuropathy in diabetes is a distal symmetric polyneuropathy, the manifestations of which are predominantly sensory and autonomic. Distal motor involvement may be an accompaniment, but it is relatively minor. This pattern of involvement does not immediately suggest a vascular causation. Ischemic neuropathy related to vasculitis, whether affecting larger or smaller arterioles, apart from often being painful, affects motor function to a greater extent than sensory. It certainly does not pick out autonomic function. Larger fibers are preferentially affected and unmyelinated axons tend to be spared. ${ }^{26}$

\section{Pattern of Fiber Loss}

The major evidence that generalized neuropathy has an ischemic basis has been derived from histopathologic observations on autopsied cases and on nerve biopsies. Sugimura and Dyck $^{28}$ and Johnson et al. ${ }^{29}$ provided clear evidence for focal areas of fiber loss in lower limb nerves and in the two patients reported by the former authors, who had an essentially symmetric polyneuropathy, it was concluded that multifocal proximal lesions had summated to produce a diffuse distal involvement. A vascular basis was considered likely. Yet the patients in both of these studies were elderly, and coexistent vascular disease would not have been unexpected and could have given rise to focal lesions superimposed on a generalized neuropathy. Indeed, there was histologic support for this in that there was evidence of an additional sensory neuropathy with greater fiber loss in dorsal than in ventral roots. Sima et al. ${ }^{30}$ found that focal nerve fiber loss was evident in sural nerve biopsies from older patients with non-insulin-dependent diabetes mellitus (NIDDM) but not in younger patients with insulin-dependent diabetes mellitus (IDDM).

The focality of nerve fiber loss was assessed by measuring the coefficient of variation for the distribution of myelinated nerve fibers in cross sections of sural nerve biopsies by Dyck et al. ${ }^{31}$ In comparison with a control series it was found that the coefficient of variation was significantly increased, which suggested the conclusion that "in diabetes nerve fiber loss is primary and multifocal" and that this indicated a vascular causation. As the series of patients investigated by Dyck et al, was elderly and mainly had NIDDM, Llewelyn et al. ${ }^{32}$ examined sural nerve biopsies from a younger series of patients with IDDM. In comparison with biopsies from an age-matched series of biopsies from organ-donor control cases, they found a coefficient of variation for diabetic nerves virtually identical to that obtained by Dyck et al. However, when the diabetic nerves were compared with those from an age-matched series of cases with type 1 hereditary motor and sensory neuropathy (HMSN), the same increase in coefficient of variation was found. There is no indication that type $1 \mathrm{HMSN}$ is a vascular disorder and such multifocality of nerve fiber loss therefore cannot be used to establish an ischemic causation for a neuropathy. The reason for this pattern of fiber loss is uncertain. In a distal length-related neuropathy it could possibly be attributed to intrafascicular segregation of fibers in terms of their peripheral distribution, for which there is some evidence derived from the results of intraneural stimulation in human subjects. ${ }^{33}$

\section{Morphologic Changes in Vessels}

There is no doubt that abnormalities of the small neural vessels are common in diabetes. Establishing that they are the cause of neuropathy is much more difficult. A lack of precise correlation would not exclude a causative relationship because of sampling problems. Conversely, finding a close correlation would not establish causation: both the neuropathy and the vascular changes could be independent manifestations of the diabetic state or, alternatively, the vascular changes could be secondary to the neuropathy.

Dyck et al. ${ }^{34}$ found an increased number of 'closed' capillaries in a series of sural nerve biopsies and found that their number was positively correlated with the severity of neuropathy as assessed by an 'index of pathology' that combined loss of myelinated nerve fibers with abnormalities in surviving fibers. In a later publication, Yasuda and Dyck ${ }^{35}$ reported that the luminal area of endoneurial capillaries was significantly greater in diabetic patients without neuropathy than in control subjects although not significantly different between diabetic patients with neuropathy and control subjects. Despite this, more 'closed' capillaries were again found in the patients with diabetic neuropathy.

Other observers have failed to support these observations. Powell, et al. ${ }^{36}$ reported that luminal diameter did not differ between diabetic patients with histologic evidence of neuro- 
pathy and control subjects. Malik et al. ${ }^{37}$ found that the perimeter of the lumen of endoneurial capillaries both in diabetic patients without neuropathy and in patients with severe neuropathy did not differ from that in organ donor control subjects. Luminal area was not reported. Bradley et al. ${ }^{38}$ found that the median area of the lumen of endoneurial capillaries for a series of patients with IDDM and neuropathy did not differ from agematched donor control cases or from patients with type 1 HMSN. The proportion of capillaries with the smallest luminal area was not higher in the diabetic patients and totally occluded vessels with obliteration of the lumen were not encountered.

Hyperplasia of the endothelium of endoneurial capillaries, with an increase both in the number of nuclei and endothelial cell area in transverse section, has been noted in diabetic neuropathy. ${ }^{36.39}$ Thickening of the basal laminal zone surrounding the capillaries has been documented by a number of investigators. ${ }^{36,37,39-41}$ Bradley et al., ${ }^{38}$ in their morphometric comparison of patients with neuropathy related to IDDM, type 1 HMSN and organ donor controls, confirmed endothelial cell hyperplasia and basal laminal thickening in diabetic neuropathy but found that this was also true of type $1 \mathrm{HMSN}$. The reduplication of the basal lamina may be related to capillary hyperplasia consequent in some way on the neuropathy. This probably varies between neuropathies with different etiologies, and examination of other disorders would be of interest as it may provide an explanation. However, the occurrence of such changes in a neuropathy such as type $1 \mathrm{HMSN}$ means that in themselves they cannot be used to substantiate a vascular causation for diabetic neuropathy.

The thickening of the pericapillary basal laminal zone found by Bradley, et al. was greater in the patients with diabetic neuropathy than in those with HMSN, although the difference did not reach statistical significance. Nevertheless, there were interesting differences between the diabetic and type $1 \mathrm{HMSN}$ patients. In the former the layers tended to remain intact whereas in the latter they became fragmented. This is possibly related to increased resistance of the basal laminal material to proteolysis in diabetics because of nonenzymatic glycation. ${ }^{42}$

Thickening of the intima of epineurial arteries, due primarily to proliferation of endothelial cells, has also been observed in diabetic neuropathy ${ }^{43}$ but the degree of thickening was not correlated with the severity of neuropathy as assessed by the amount of nerve fiber loss.

\section{Intraluminal Changes}

Timperley, et al. ${ }^{44}$ drew attention to the presence of aggregates of platelets and fibrin within the lumina of neural blood vessels in patients with diabetic neuropathy. These were not observed in any of the 27 cases investigated by Bradley et al. ${ }^{38}$ Other factors that could affect delivery of oxygen to the tissues include increased blood viscosity, reduced deformability of red blood cells and alterations in the dissociation constant of hemoglobin secondary to nonenzymatic glycation. Such changes are likely to be a feature of poorly controlled, severely diabetic patients. Whether they play any part in the production of the sensory symptoms that may occur in such patients, and which are rapidly relieved by achieving glycemic control, is uncertain.

\section{Intraneural Oxygenation}

Intraneural oxygen tension was found to be less in a group of patients with diabetic neuropathy than in control subjects. ${ }^{45}$ This was taken as favoring a vascular causation for diabetic neuropathy. This conclusion cannot be accepted unreservedly as the control subjects were appreciably younger. In addition, transcutaneous recordings of lower limb tissue oxygen tension have not shown reductions in patients with diabetic neuropathy although they demonstrated a failure for oxygen tension to increase as well on warming, suggesting sympathetic denervation. ${ }^{46}$ Direct observations on capillary blood flow in the nail fold vasculature of the toes has revealed an increase in blood flow and no evidence of capillary closure ${ }^{47}$ It will be important to obtain further direct measurements of intraneural oxygen tension in patients with diabetic neuropathy in comparison with agematched control subjects. The morphologic abnormalities have been found to be greater in endoneurial than in skin vessels. ${ }^{37}$

\section{Vascular Permeability}

There have been conflicting reports of the permeability of endoneurial blood vessels in experimental diabetes. The present evidence suggests an increased permeability for small molecules ${ }^{48}$ but not for larger molecules. For human diabetic neuropathy an increased concentration of plasma macromolecules, including albumin and immunoglobulin, has been found in the endoneurium. ${ }^{49.50}$ On the other hand, Patel et al. ${ }^{51}$ have recently shown that permeation of glycated albumin into nerve is significantly greater than for native albumin and this may be at least part of the explanation, rather than any abnormality of the vessels themselves.

\section{Animal Models}

Tuck et al., ${ }^{52}$ in streptozotocin-diabetic rats, found that endoneurial oxygenation and blood flow were reduced in the sciatic nerve and that vascular resistance was increased in the absence of any significant change in systemic blood pressure. The reduction in nerve conduction velocity that is found in this model can be partially reversed by rearing the animals in hyperbaric oxygen. ${ }^{53}$ The relevance of these findings to human diabetic neuropathy is speculative as significant degenerative changes with axonal degeneration and demyelination do not develop in this model, as demonstrated by Sharma and Thomas $^{54}$ and others. Moreover, Zochodne and Ho, ${ }^{55}$ while confirming reduced intraneural oxygenation in streptozotocin-diabetic rats, failed to find evidence of diminished endoneurial blood flow.

\section{Neuropathy Related to Chronic Respiratory Insufficiency}

The occurrence of neuropathy in patients with respiratory insufficiency has been adduced as supportive evidence that hypoxia is responsible for diabetic neuropathy. Appenzeller et al. ${ }^{56}$ reported the presence of a distal polyneuropathy in 7 out of 8 patients with advanced chronic obstructive respiratory disease. The role of hypoxia in the explanation of neuropathy was difficult to assess in view of severe accompanying weight loss and malnutrition. Narayan and Ferranti ${ }^{57}$ and Faden et al..$^{58}$ later confirmed the occurrence of neuropathy in patients with chronic respiratory insufficiency, and Vila et al. ${ }^{59}$ found electrophysiologic evidence of an axonopathy. Changes in neural blood vessels have also been described. ${ }^{60}$ It seems likely that a mild neuropathy may develop, for reasons not yet established, in patients with chronic respiratory insufficiency, yet its relevance to diabetic neuropathy is dubious. McLeod and Pollard ${ }^{61}$ concluded that it "seems to be of little clinical importance and so far has 
not been described as a presenting or dominant clinical feature in any patients with chronic obstructive pulmonary disease". This has been the experience of the author.

\section{Metabolic Hypotheses}

\section{Insulin Deficiency}

Peripheral nerve, like the central nervous system, is not dependent on insulin for the regulation of glucose uptake or energy metabolism. ${ }^{62}$ This has been attributed to the presence of the blood-nerve and blood-brain barriers. Autonomic and sensory ganglia lack an efficient blood-nerve barrier ${ }^{63}$ and the question therefore arises as to whether they may be insulin-dependent. We have failed to detect any influence of insulin on glucose or amino acid uptake by dorsal root ganglia (N. Patel, D. Wright and P.K. Thomas, unpublished results). Any effects of insulin deficiency or tissue unresponsiveness would therefore have to be by less direct methods.

\section{Sorbitol Accumulation}

A major metabolic disturbance in peripheral nerve, in most of the experimental models and in man, is the accumulation of sorbitol and fructose in peripheral nerve ${ }^{64}$ This is related to increased flux in the polyol pathway consequent upon saturation of the hexokinase shunt, with resultant accumulation of glucose in the nerve. In the polyol pathway, glucose is converted to sorbitol by aldose reductase and sorbitol to fructose by a polyol dehydrogenase. Evidence that this may be involved in the production of diabetic neuropathy is derived from observations on the use of aldose reductase inhibitors to prevent the accumulation of sorbitol in nerve. It is now conclusively documented both from animal ${ }^{65}$ and human ${ }^{66}$ studies that nerve conduction velocity can be improved by aldose reductase inhibitors. Only modest evidence of improvement has been shown in clinical studies, but for the reasons given in the Introduction, substantial improvement is probably an impossible goal in treatment trials. Further long-term trials to establish whether deterioration can be prevented are merited. Encouraging evidence that aldose reductase inhibitors may increase regenerative sprouting of axons and a greater degree of remyelination has been provided by Sima et al. ${ }^{67}$ in serial sural nerve biopsies performed before and after 1 year of treatment with an aldose reductase inhibitor.

\section{Myo-inositol Depletion/Reduced $\mathrm{Na}^{+} \mathrm{K}^{+}$-ATPase Activity}

A further metabolic abnormality identified in peripheral nerve in experimental diabetes in animals is a reduction of myoinositol content. This has been linked by Greene and his coworkers to reduced $\mathrm{Na}^{+} \mathrm{K}^{+}$-ATPase activity, this observation having originally been made by Das, et al. ${ }^{68}$ In a series of studies in streptozotocin-diabetic rats, Greene and his collaborators have related myo-inositol deficiency in nerve to the occurrence of neuropathy, but this has largely been based on changes in nerve conduction velocity as an indicator of neuropathy. It was shown that both the deficit in conduction velocity and the reduced $\mathrm{Na}^{+} \mathrm{K}^{+}$-ATPase activity could be improved by dietary myo-inositol supplementation in the absence of any change in the severity of the hyperglycemia. ${ }^{69}$ There are difficulties, however, in accepting this hypothesis unreservedly. The relationship between myo-inositol concentrations in nerve and $\mathrm{Na}^{+} \mathrm{K}^{+}$ATPase activity is not a simple one. In experimental galactose- induced neuropathy, $\mathrm{Na}^{+} \mathrm{K}^{+}$-ATPase activity is increased instead of being reduced, despite there being a reduced myo-inositol concentration in nerve. ${ }^{70,71} \mathrm{~A}$ major obstacle in applying the hypothesis to human diabetic neuropathy is the fact that myoinositol concentrations are not reduced in human diabetic neuropathy. ${ }^{72}$ It is possible, however, that a small pool of phosphoinositides, derived from myo-inositol, is reduced, and that measurements of total myo-inositol concentration may not reflect this.

\section{Altered Protein Synthesis and Axonal Transport}

The uptake of amino acids and their incorporation into protein is reduced in dorsal root ganglia in streptozotocin-induced diabetic rats. ${ }^{73}$ Slow axonal transport has been shown to be impaired; both the velocity of slow component a (Sca) and the amount of material translocated in Sca have been found to be diminished. ${ }^{74}$ Structural proteins, including neurofilaments, are transported in Sca. They are largely responsible for determining axonal caliber. The reduction in the experimental animal is relatively small and the application of this finding to human diabetic neuropathy is uncertain. Although axonal atrophy has been found by some authors, ${ }^{75}$ it was not detected by Sugimura and Dyck $^{76}$ or by Llewelyn et al. ${ }^{77}$

\section{Nonenzymatic Glycation}

Hyperglycemia leads to the nonenzymatic glycation of proteins. No deleterious effects of this process on neuronal, axonal or Schwann cell function have so far been demonstrated, but it could contribute to vasculopathy. ${ }^{78}$

\section{Neurotrophic Effects}

The clinical features of the common diabetic sensory and autonomic polyneuropathies are suggestive of a neuronal system degeneration that has a selective effect on particular sets of neurons. Pathologically, a distal 'dying-back' axonopathy has been demonstrated. ${ }^{79}$ Peripheral nerve has been shown to possess insulin receptors, ${ }^{80,81}$ the function of which is uncertain, as peripheral nerve, like the central nervous system, does not depend upon insulin for energy metabolism. It has been suggested that in the CNS insulin receptors are involved in longer term neurotrophic effects related to the maintenance of cell structure and integrity. It is conceivable that diabetic polyneuropathy could be on this basis, but a selective effect on peripheral nerve would have to be explained.

\section{IMmunologic Mechanisms}

The possibility that immunologic mechanisms are involved in severe diabetic autonomic neuropathy has been raised by the finding of inflammatory infiltrates in autonomic ganglia of cases that have come to autopsy. ${ }^{82}$ The presence of antisympathetic ganglion antibodies has also been demonstrated in patients with insulin-dependent diabetes, and is correlated with a diminished catecholamine response on standing. ${ }^{83}$

\section{Conclusions and Synthesis}

A wide variety of mechanisms has been advanced as possibly being responsible for diabetic neuropathy. They should not be viewed as being mutually exclusive. The wide spectrum of clinical manifestations in the peripheral nervous system that may occur in patients with diabetes mellitus is a strong pointer 
towards the existence of multiple causal factors. It seems likely that in older patients in whom focal and multifocal neuropathies are more frequent, vascular factors will be more important. In the younger patients in whom a symmetric polyneuropathy is the usual presentation, there is current argument as to whether this is also vascular in origin, or whether it has a more direct metabolic basis. The writer favors the latter possibility, but the precise nature of the metabolic disturbance still eludes discovery.

\section{REFERENCES}

I. Jakobsen J, Christiansen JS, Kristoffersen I, et al. Autonomic and somatosensory function after 2 years of continuous subcutaneous insulin in type 1 diabetes. Diabetes 1988; 37: 452-455.

2. Kennedy WR, Navarro X, Goetz FC, et al. Effects of pancreatic transplantation on diabetic neuropathy. N Engl J Med 1990; 322: 1031-1037.

3. Gregersen G. Diabetic neuropathy: influence of age, sex, metabolic control, and duration of diabetes on motor conduction velocity. Neurology (Minneap) 1967; 17: 972-980.

4. Ward JD, Barnes CG, Fisher DJ, et al. Improvement in nerve conduction following treatment in newly-diagnosed diabetics. Lancet 1971; 1: 428-431.

5. Steiness IB. Vibratory perception in diabetics during arrested blood flow to the limb. Acta Med Scand 1959; 163: 195-205.

6. Ritchie JM, A note on the mechanism of resistance to anoxia and ischaemia in pathophysiological mammalian myelinated nerve. $\mathrm{J}$ Neurol Neurosurg Psychiatry 1985; 48: 274-277.

7. Archer AG, Watkins PJ, Thomas PK, et al. The natural history of acute painful neuropathy in diabetes mellitus. J Neurol Neurosurg Psychiatry 1983; 46: 491-499.

8. Subramony SH, Wilbourn AJ. Diabetic proximal neuropathy. Clinical and electromyographic studies. J Neurol Sci 1982; 53: 293-301.

9. Sima AAF, Lattimer SA, Yagihashi S, et al. Axoglial dysjunction. A novel structural lesion responsible for poorly reversible nerve conduction slowing in the spontaneously diabetic BB rat. J Clin Invest 1986; 77: 474-479.

10. Sima AAF, Zang WX, Tze WJ, et al. Diabetic neuropathy in the streptozotocin diabetic rat and the effect of allogenic islet cell transplantation. Diabetes 1988; 37: 1129-1136.

11. Pryce TD. On diabetic neuritis, with a clinical and pathological description of three cases of diabetic pseudo-tabes. Brain 1983; 16: 416-434.

12. Woltman HW, Wilder RM. Diabetes mellitus: pathological changes in the spinal cord and peripheral nerves. Arch Intern Med 1929; 44: 576-603.

13. Hutchinson EC, Liversedge LA. Neuropathy in peripheral vascular disease: its bearing on diabetic neuropathy. Q J Med 1956; 25 : 269-274.

14. Eames RA, Lange LS. Clinical and pathological study of ischaemic neuropathy. J Neurol Neurosurg Psychiatry 1967; 30: 215-226.

15. Chopra JS, Hurwitz LJ. A comparative study of peripheral nerve conduction in diabetes and nondiabetic occlusive peripheral vascular disease. Brain 1969; 92: 83-96.

16. Chopra JS, Hurwitz LJ. Internodal length of sural nerve fibres in chronic occlusive vascular disease. J Neurol Neurosurg Psychiatry 1967; 30: 201-214.

17. Fagerberg SE. Diabetic neuropathy: a clinical and histological study on the significance of vascular affections. Acta Med Scand 1959; 164 (Suppl): 354.

18. Harriman D. Ischaemic factor in diabetic neuropathy. In: Proc 4th Internal Cong Neuropathol. Stuttgart, Thieme, 1962; 3: 164.

19. Dolman CL. The morbid anatomy of diabetic neuropathy. Neurology (Minneap) 1963; 13: 135-142.

20. Greenbaum D, Richardson PC, Salmon MV, et al. Pathological observations on six cases of diabetic neuropathy. Brain 1964; 87 : 201-204.

21. Thomas PK, Lascelles RG. The pathology of diabetic neuropathy. Q J Med 1966; 35: 485-509.
22. Neary D, Ochoa J, Gilliatt RW. Sub-clinical entrapment neuropathy in man. J Neurol Sci 1975; 24: 283-298.

23. Gilliatt RW, Wilson TG. A pneumatic-tourniquet test in the carpaltunnel syndrome. Lancet 1962; 2: 11-13.

24. Sunderland $\mathbf{S}$. The nerve lesion in the carpal tunnel syndrome. $J$ Neurol Neurosurg Psychiatry 1976; 39: 615-626.

25. Asbury AK, Aldredge H, Hershberg R, et al. Oculomotor palsy in diabetes mellitus: a clinico-pathological study. Brain 1970; 93: 555-566.

26. Fujimura H, Lacroix C, Said G. Vulnerability of nerve fibres to ischaemia: a quantitative study. Brain 1991; 114: 1929-1942.

27. Raff M, Sangalang V, Asbury AK. Ischemic mononeuropathy multiplex associated with diabetes mellitus. Arch Neurol (Chic) 1968; 18: 487-498.

28. Sugimura K, Dyck PJ. Multifocal fiber loss in proximal sciatic nerve in symmetric distal diabetic neuropathy. J Neurol Sci 1982; 53: 501-509.

29. Johnson PC, Doll SC, Cromer DW. Pathogenesis of diabetic neuropathy. Ann Neurol 1986; 19: 450-457.

30. Sima AAF, Nathaniel V, Bril V, et al. Histopathological heterogeneity of neuropathy in insulin-dependent and non-insulin-dependent diabetics and demonstration of axoglial dysjunction in human diabetic neuropathy. J Clin Invest 1988; 81: 349-364.

31. Dyck PJ, Lais A, Karnes JL, et al. Fiber loss is primary and multifocal in sural nerves in diabetic polyneuropathy. Ann Neurol 1986; 19: 425-439.

32. Llewelyn JG, Thomas PK, Gilbey SG, et al. Pattern of myelinated fibre loss in the sural nerve in neuropathy related to type 1 (insulin-dependent) diabetes. Diabetologia 1988; 31: 162-167.

33. Hallin RG. Microneurography in relation to intraneural topography: somatotopic organization of median nerve fascicles in humans. J Neurol Neurosurg Psychiatry 1990; 53: 736-744.

34. Dyck PJ, Hansen S, Karnes J, et al. Capillary number and percentage closed in human diabetic sural nerve. Proc Natl Acad Sci USA 1985; 82: 2513-2517.

35. Yasuda H, Dyck PJ. Abnormalities of endoneurial microvessels and sural nerve pathology in diabetic neuropathy. Neurology 1987; 37: 20-28.

36. Powell HC, Rosoff J, Myers RR. Microangiopathy in human diabetic neuropathy. Acta Neuropathol (Berl) 1985; 68: 295-305.

37. Malik RA, Newrick P, Sharma AK, et al. Microangiopathy in human diabetic neuropathy: relationship between capillary abnormalities and the severity of neuropathy. Diabetologia 1989; 32: 92-102.

38. Bradley J, Thomas PK, King RHM, et al. Morphometry of endoneurial capillaries in diabetic sensory and autonomic neuropathy. Diabetologia 1990; 33: 611-618.

39. Timperley WR, Boulton AJM, Davies-Jones GAB et al. Small vessel disease in progressive diabetic neuropathy with good control. J Clin Pathol 1985; 38: 1030-1041.

40. Vital C, Leblanc M, Vallat JM, et al. Études ultrastructurale du nerf périphérique chez 16 diabétiques sans neuropathie clinique. Comparison avec 16 neuropathies diabétiques et 16 neuropathies non diabétiques. Acta Neuropathol (Berl) 1974; 30: 63-72.

41. Behse F, Buchthal F, Carlsen F. Nerve biopsy and conduction studies in diabetic neuropathy. J Neurol Neurosurg Psychiatry 1977; 40: $1072-1082$

42. King RHM, Llewelyn JG, Thomas PK, et al. Diabetic neuropathy: abnormalities of Schwann cell and perineurial basal laminae. Implications for diabetic vasculopathy. Neuropathol Appl Neurobiol 1989; 15: 339-355.

43. Korthals JK, Gieron MA, Dyck PJ. Intima of epineurial arterioles is increased in diabetic neuropathy. Neurology 1988; 38: 15821586.

44. Timperley WR, Ward JD, Preston FE, et al. A reassessment of vascular factors in relation to intravascular coagulation. Diabetologia 1976; 12: 237-243.

45. Newrick PG, Wilson AJ, Jakubowski J, et al. Sural nerve oxygen tension in diabetes. Br Med J 1986; 293: 1053-1054.

46. Gaylarde PM, Fonseca VA, Llewelyn JG, et al. Transcutaneous oxygen tension in the legs and feet of diabetics. Diabetes 1988; 37: 714-716. 
47. Flynn MD, Edmonds ME, Tooke JE, et al. Direct measurements of capillary blood flow in the diabetic neuropathic foot. Diabetologia 1988; 31: 652-656.

48. Rechthand E, Smith Q, Latker C, et al. Altered blood-nerve barrier permeability to small molecules in experimental diabetes mellitus. J Neuropathol Exp Neurol 1987; 46: 302-314.

49. Ohi T, Poduslo JF, Dyck PJ. Increased endoneurial albumin in diabetic polyneuropathy. Neurology 1985; 35: 1790-1791.

50. Poduslo JF, Curran GL, Dyck PJ. Increase in albumin, IgG, and IgM blood-nerve barrier indices in human diabetic neuropathy. Proc Natl Acad Sci USA 1988; 85: 4879-4883.

51. Patel NJ, Misra VP, Dandona P, et al. The effect of non-enzymatic glycation of serum proteins on their permeation into peripheral nerve in normal and streptozotocin-diabetic rats. Diabetologia 1991; 34: 78-80.

52. Tuck RR, Schmelzer JD, Low PA. Endoneurial blood flow and oxygen tension in the sciatic nerve of rats with experimental diabetic neuropathy. Brain 1984; 107: 935-950.

53. Low PA, Tuck RR, Dyck PJ, et al. Prevention of some electrophysiologic and biochemical abnormalities with oxygen supplementation in experimental diabetic neuropathy. Proc Natl Acad Sci USA 1984; 81: 6894-6898.

54. Sharma AK, Thomas PK. Peripheral nerve structure and function in experimental diabetes. J Neurol Sci 1974; 23: 1-15.

55. Zochodne DW, Lam T Ho. Normal hydrogen clearance but lowered oxygen tension in the sciatic nerve endoneurium of young diabetic animals. Can J Neurol Sci 1991: in press (Proceedings of 26th Canadian Congress of Neurological Science).

56. Appenzeller O, Parks RD, MacGee J. Peripheral neuropathy in chronic disease of the respiratory tract. Am J Med 1968; 44: 873-880.

57. Narayan M, Ferranti R. Nerve conduction impairment in patients with respiratory insufficiency and severe chronic hypoxemia. Arch Phys Med Rehab 1978; 59: 188-192.

58. Faden A, Mendoza E, Flynn F. Subclinical neuropathy associated with chronic obstructive pulmonary disease. Possible pathophysiologial role of smoking. Arch Neurol 1976; 38: 639-642.

59. Vila A, Reymond F, Paramelle B, et al. Neuropathies et insufficiantes respiratoire chronique: étude électrophysiologique. Rev Electroencephalogr Neurophysiol Clin 1985; 15: 331-340.

60. Stoebner P, Mezin P, Vila A, et al. Microangiopathy of endoneurial vessels in hypoxemic chronic obstructive pulmonary disease (COPD). A quantitative ultrastructural study. Acta Neuropathol (Berl) $1989 ; 78: 388-395$.

61. McLeod JG, Pollard JG. Neuropathies in systemic diseases: hidden and overt. In: Asbury AK, Gilliatt RW, eds. Peripheral Nerve Disorders: A Practical Approach. London: Butterworths, 1984: 92-125.

62. Greene DA, Winegrad AI. In vitro studies of the substrates for energy production and the effects of insulin on glucose utilization on the neural components of peripheral nerve. Diabetes 1979; 28: 878-887.

63. Jacobs JM, MacFarlane RM, Cavanagh JB. Vascular leakage in the dorsal root ganglia of the rat studied with horseradish peroxidase. J Neurol Sci 1976; 29: 95-107.

64. Gabbay KH, Merola LO, Field RA. Sorbitol pathway: presence in nerve and cord with substrate accumulation in diabetes. Science 1966; 151: 209-210.

65. Yue DK, Hanwell MA, Satchell PM, et al. The effects of aldose reductase inhibition on nerve sorbitol and myo-inositol in diabetic and galactosemic rats. Metabolism 1984; 33: 1119-1122.
66. Judzewitsch RG, Jaspan JB, Polonsky KS, et al. Aldose reductase inhibition improves nerve conduction velocity in diabetic patients. N Engl J Med 1983; 308: 119-125.

67. Sima AAF, Bril V, Nathaniel V, et al. Regeneration and repair of myelinated fibers in sural-nerve biopsy specimens from patients with diabetic neuropathy treated with sorbinil. $\mathrm{N}$ Engl J Med 1988; 319: 548-555.

68. Das PK, Bray GM, Aguayo AJ, et al. Decreased ouabain-sensitive sodium-potassium ATPase activity in sciatic nerves of rats with streptozotocin-induced diabetes. Exp Neurol 1976; 53: 285-288.

69. Greene DA, Lattimer SA, Sima AAF. Sorbitol, phosphoinositides, and sodium-potassium ATPase in the pathogenesis of diabetic complications. N Engl J Med 1987; 316: 599-606.

70. Lambourne JE, Tomlinson DR, Brown AM, et al. Opposite effects of diabetes and galactosaemia on adenosine triphosphatase activity in rat nervous tissue. Diabetologia $1987 ; 30: 360-362$.

71. Llewelyn JG, Patel NJ, Thomas PK, et al. Sodium, potassium adenosine triphosphatase activity in peripheral nerve tissue of galactosaemic rats. Effects of aldose reductase inhibition. Diabetologia 1987; 30: 971-972.

72. Dyck PJ, Zimmerman BR, Vilen TH, et al. Nerve glucose, fructose, sorbitol, myo-inositol, and fiber degeneration and regeneration in diabetic neuropathy. $N$ Engl J Med 1988; 319: 542-548.

73. Thomas PK, Wright DW, Tzebelikos E. Amino acid uptake by dorsal root ganglia from streptozotocin-diabetic rats. J Neurol Neurosurg Psychiatry 1984; 47: 912-916.

74. Jakobsen J, Sidenius P. Decreased axonal transport of structural proteins in streptozotocin diabetic rats. J Clin Invest 1980; 66: 292-297.

75. Sharma AK, Britland ST, Young RJ, et al. Morphological abnormalities in the sural nerve of patients with and without clinical syndromes of diabetic neuropathy. In: Ward J, Goto Y, eds. Diabetic Neuropathy. Chichester: John Wiley, 1990: 29-45.

76. Sugimura K, Dyck PJ. Sural nerve myelin thickness and axis cylinder caliber in human diabetes. Neurology (NY) 1981; 31: 10871091.

77. Llewelyn JG, Gilbey SG, Thomas PK, et al. Sural nerve morphometry in diabetic autonomic and painful sensory neuropathy: a clinicopathological study. Brain 1991; 114: 867-892.

78. Brownlee $\mathbf{M}$, Cerami M, Vlassara $H$. Advanced glycosylation end products in tissue and the biochemical basis of diabetic complications. N Engl J Med 1988; 318: 1315-1321.

79. Said G, Slama G, Selva J. Progressive centripetal degeneration of axons in small fibre type diabetic polyneuropathy. A clinical and pathological study. Brain 1983; 106: 791-807.

80. Waldbillig RJ, LeRoith D. Insulin receptors in the peripheral nervous system: a structural and functional analysis. Brain Res 1987; 409: 215-220.

81. Llewelyn JG, Patel NJ, Thomas PK, et al. Insulin receptors in sensory and sympathetic ganglia and in peripheral nerve. $J$ Neurol 1988; 235: S16.

82. Duchen LW, Anjorin A, Watkins PJ, et al. Pathology of autonomic neuropathy in diabetes. Ann Intern Med 1980; 92: 301-303.

83. Brown FM, Brink SJ, Freeman R, et al. Anti-sympathetic nervous system antibodies. Diminished catecholamines with orthostasis. Diabetes 1989; 38: 938-941. 